\title{
A Comparative Study of Social Impacts of the COVID-19 Pandemic on Republic of Korea, Japan, and Taiwan
}

\author{
Angela Lo', Bang-Ook Jun², Vincent Shieh ${ }^{3}$, Clay M. Starlin ${ }^{4}$, Satoshi Sugahara ${ }^{5}$, and Dian-Jeng Li ${ }^{6,7} \bowtie$ \\ ${ }^{1}$ Faculty of Medicine, College of Medicine, Kaohsiung Medical University, Kaohsiung, Taiwan \\ ${ }^{2}$ Department of Biology, College of Natural Science, Gangneung-Wonju National University, Gangneung, Republic of Korea \\ ${ }^{3}$ Graduate Institute of Gender Education, National Kaohsiung Normal University, Kaohsiung, Taiwan \\ ${ }^{4}$ Department of Education, Worcester State University, Worcester, MA, USA \\ ${ }^{5}$ School of Business Administration, Kwansei Gakuin University, Nishinomiya, Japan \\ ${ }^{6}$ Department of Addiction Science, Kaohsiung Municipal Kai-Syuan Psychiatric Hospital, Kaohsiung, Taiwan \\ ${ }^{7}$ Department of Nursing, Meiho University, Pingtung, Taiwan
}

Objective The frequency of various disasters has become a 21st century global crisis. The biological-disaster of the coronavirus disease of 2019 (COVID-19) gave rise to a multi-dimensional global impact. The 25 items of Societal Influences Survey Questionnaire (SISQ) was developed to assess various categories of social influence during the pandemic. This study compares the SISQ scores of Taiwan, Republic of Korea (Korea) and Japan.

Methods Persons living in Korea, Japan, and Taiwan were recruited and evaluated through an SISQ online survey. The SISQ is composed of 25 items each with a 4-point Likert scale. The SISQ assesses the following six factors: self-restraint, social impact, government policy, social cost, concern of infection, and awareness of information. A principal factor analysis and reliability (Cronbach's alpha) were performed to validate the SISQ. The analysis of variance (ANOVA) and post-hoc analysis was conducted to explore the differences between groups.

Results The SISQ had acceptable reliabilities, and accounted for $58.86 \%$ of the variance. The significance for ANOVA with post-hoc analysis showed that scores of self-restraints ranked highest in Japan followed by Taiwan and Korea. Taiwanese scored lower than other nations regarding the concern of infection. Koreans scored higher in awareness of information than the other two nations. The effect of age and marital status were also estimated.

Conclusion The SISQ comprehensively evaluate multiple domains of social influence, and it manifests the divergence of social impacts across the three nations.

Psychiatry Investig 2021;18(10):1006-1017

Keywords COVID-19; Biological disaster; Social impact; National comparisons; Survey research.

\section{INTRODUCTION}

The coronavirus disease of 2019 (COVID-19) increases in

\footnotetext{
Received: June 28, 2021 Revised: August 13, 2021

Accepted: August 18, 2021

$\triangle$ Correspondence: Satoshi Sugahara, MEd, PhD

School of Business Administration, Kwansei Gakuin University, 1-155 Uega-

hara Ichiban-Cho. Nishinomiya, Hyogo 662-8501, Japan

Tel: +81-798-54-7453, Fax: +81-798-51-0903

E-mail: billionaire1210@gmail.com

$\triangle$ Correspondence: Dian-Jeng Li, MD

Department of Addiction Science, Kaohsiung Municipal Kai-Syuan Psychiatric Hospital, 130, Kai-Syuan 2nd Rd., Ling-Ya District, Kaohsiung 802, Taiwan Tel: +886-7-7513171 \#2371, Fax: +886-7-716-1843

E-mail: edcrfvm45@hotmail.com

(c) This is an Open Access article distributed under the terms of the Creative Commons Attribution Non-Commercial License (https://creativecommons.org/licenses/by$\mathrm{nc} / 4.0$ ) which permits unrestricted non-commercial use, distribution, and reproduction in any medium, provided the original work is properly cited.
}

spread the number of confirmed cases and deaths are also on a rapid rise. Inadequate and imprecise information has exaggerated the impact of COVID-19 further exacerbating the global crisis. ${ }^{1}$ The outbreak is not only a biological event, but a public health disaster and we need to understand, from a social, historical and cultural perspective the risks and how to manage such biological disasters. ${ }^{2}$ From the experience to combat severe acute respiratory syndrome (SARS) and other natural disasters in Taiwan, we have established a partnership between community healthcare workers and epidemic prevention workers, developing a working model for a resilient community. This model of epidemic prevention to ensure biological and social safety is the key to proper control of the COVID-19 epidemic in Taiwan. ${ }^{1,3}$

In the recent decades, Taiwan, Japan, and South Korea have 
faced similar outbreaks like COVID-19 and have overcome difficulties when encountering these transnational threats. These three nations have been conscientiously dealing with the COVID-19 by drawing from the past years of SARS experiences. However, the multi-dimensional strategies for COVID-19 may have divergence across these nations. In response to the rapid epidemic of COVID-19, Korea has consolidated government and community medical resources, redesigned the diagnosis and treatment dispersal system, and adopted the strategies to combat community transmission. ${ }^{4}$ The containment strategy was also applied in the Korea, indicating the efforts on the quarantine and contact tracing system. ${ }^{5}$ The drive-through and walkthrough screening stations were built for early detection of confirmed cases in communities in Korea. ${ }^{6}$ On the other hand, Japan has implemented mitigation strategies to reduce the spread of virus transmission. ${ }^{5}$ Patients with very mild illness of COVID-19 were advised to stay home, and asymptomatic people were discouraged from regular screen of coronavirus. ${ }^{7}$ In Taiwan, the strategy of infection control was similar to containment strategy. The border control, application of big data analytics, contact tracing system, policies of quarantine and experienced teams of officials made the public less concerned about being infected. ${ }^{8}$ The above-mentioned literature addresses the need for government planning strategies and consolidating medical resources. However, it is interested to explore the impacts of divergent policies on the publics across three nations.

The COVID-19 outbreak is imposing an unprecedented burden on our lives. Agricultural, industrial, manufacturing, aviation, tourism, and sports industries were affected by the socioeconomic impact of the Great Depression. People worried about the financial market crash, unfair distribution of medical resources and incompetent leadership. Such worries create anxiety, conflict among people, lifestyle imbalances and alienation between people. ${ }^{9}$ COVID-19 seriously changed the lives of many people impacting mental health, causing fear, trauma, depression, and anxiety. ${ }^{10}$ Moreover, the epidemic stirred anxiety, fear and worry among people globally, forcing the concept and actions of people maintaining their health. ${ }^{11}$ The World Health Organization (WHO) has also expressed concern over the pandemic's impacts on mental health and psycho-social well-being. The WHO has also called for a global consolidation of funding and resources to overcome the psychological influences. ${ }^{11}$ This speaks to the importance of investigating on the effects of the pandemic on people's emotional and mental well-being.

Previous study indicated that mental health concerns of people impacted by the coronavirus pandemic have not been adequately addressed. ${ }^{12}$ There was widespread psychological stress but positive compliance with wearing masks and washing hands for personal hygiene. ${ }^{13}$ During the pandemic, certain professional or age groups are more susceptible to the adverse psy- chological impact. A nation-wide questionnaire survey in Japan investigated that the life-oriented approach captures various life activities and decisions in terms of life domains, and emphasizes inter-behavioral inter-dependencies. ${ }^{14}$ The authors also found that the COVID-19 outbreak impacted almost all aspects of Japanese life, such as cancelling social activities based on voluntary social distancing. ${ }^{14}$ In addition, personal experience with the virus, individualistic and prosocial values, hearing about the virus from friends and family, trust in government, science, and medical professionals, personal knowledge of government strategy, and personal and collective efficacy ${ }^{15}$ were all significantly related to risk perception. Therefore, it will be interested in estimating the variability across countries, including individualistic worldviews, personal experience, prosocial values, and social amplification through friends and family.

The WHO has called for every nation to prepare international research funding, to evaluate risks of the epidemic, and to build strategies against biological disasters. ${ }^{16}$ COVID- 19 has brought about a global crisis, where no one is spared, and global actions and responses are needed. The Sendai Framework for Disaster Risk Reduction 2015-2030 was used to gather research resources relating to technological developments, disaster prevention and reduction and development of social consensus. ${ }^{17}$ This process emphasizes the use of scientific research as the foundation of strategic plans and actions. ${ }^{17}$ The current research adapted the 15-items of Societal Influences Survey Questionnaire (SISQ) ${ }^{18}$ to investigate the social influences of COVID-19 and compare the results between three Northeast Asian countries-Taiwan, South Korea and Japan. Through conducting comparative studies across international borders, it enables investigators to exchange epidemic risk management strategies and thus enhances research outcomes for pandemic prevention. ${ }^{19}$ Hence, inter-disciplinary, inter-cultural and international research can have a positive influence on epidemic prevention. Recently, researchers in many countries adapted existing formats and designed new formats to conduct the psychosocial studies estimating impacts of COVID-19. The Coronavirus Anxiety Scale (CAS) was developed and evaluated for use as a survey tool, ${ }^{12}$ and another scale, the Fear of COVID-19 Scale (FCV-19S), was developed based on McCoach et al. $\mathrm{s}^{20}$ recommendations on instrument development in the affective domain. However, these tools only focused on the affective domains in facing with COVID-19. Therefore, the aim of the current study is to develop the 25-litms of SISQ to comprehensively estimate the multidimensional impacts of COVID-19. The 25-itms SISQ contains a lager coverage of domains to estimate the multidimensional impacts of COVID-19 on the publics, including the coping strategies against COVID-19 (social distance), affective response to COVID-19 (social anxiety), the confidence as well as compliance to the government's strategies (social desirability), risk perception of CO- 
VID-19 (social adaptation), preparation for personal hygiene (social costs), and motivation to acquire COVID-19 related knowledge (social information). Another aim of the current study is to compare the difference of 25 -items of SISQ across the three nations.

\section{METHODS}

\section{Participants and ethics}

We recruited participants through online advertisements posted on social media, such as Facebook or Line in Taiwan (April 8 to April 18, 2020), Korea (April 11 to April 16, 2020), and Japan (April 11 to April 18, 2020). The online questionnaire was developed on Google Forms, and the announcement of the current study was exhibited in the first page. Participation was voluntary and survey responses were anonymous. Subjects were eligible for this study if they agreed to fill in the online survey, and participants were given not provided any compensation for participating. This study was approved by the Human Research Ethics Committee (HREC) of National Cheng Kung University (Approval number: NCKU HREC-E-109-066-2).

\section{Measures}

The original 15-items of Societal Influences Survey Questionnaire (SISQ) were developed to assess social influences among publics during COVID-19 pandemic. With well-established reliability and validity, ${ }^{18}$ the SISQ can be used to comprehensively evaluated the social influences with 5 categories as follows: social distance, social anxiety, social desirability, social information, and social adaptation. In addition to extend the applicability, the 25-items of SISQ were developed with six domains of assessment on social distance, social anxiety, social desirability, social costs, social adaptation, and social information. In order to satisfy content and face validity requirements, expert meetings were scheduled to review the adequacy of content, quality of translation across the three native languages and items were revised in accordance with cultural standards. It was composed of 4-point Likert scale, with scores ranging from 1 (never), 2 (seldom), 3 (occasional), and 4 (often). Higher scores represent more impact on each category. The following demographic variables were recorded for each participant: nationality, age, marital status, and gender. All of the demographic information was identified as categorical fact.

\section{Statistical analysis}

All of the analytics were conducted through SPSS statistical software (IBM SPSS Statistics for Windows, Version 23.0. IBM Corp., Armonk, NY, USA). Descriptive analysis was used to summarize the variables. We applied the exploratory principal component analysis (PCA) to extract six factorial scores from the 25-item SISQ, since there were too many variables to analyze. The principle of component analysis is to reduce the number of factors needed to best represent the interrelationships among the set of variables. Initially, assumption tests were performed to assess the suitability of the data for factor analysis. This was done through Varimax rotation due to the assumption that the factors were correlated. The Kaiser-Mayer-Olkin (KMO) measure of sampling adequacy and Bartlett testing were applied. A KMO value of $>0.60$ and statistically significant value of $\mathrm{p}<0.05$ from Bartlett testing indicated the data was adequate for factor analysis. ${ }^{21}$ Total variance explained, and factor loadings were also estimated. The amount of variance indicates how well a relevant construct can be measured. In the social sciences, it is common to consider a solution that accounts for 50 percent of the total variance as satisfactory. ${ }^{22}$ The internal consistency (Cronbach alpha values) was used to test the reliability of each factor, where a value greater than 0.5 indicated moderate reliability. ${ }^{23}$

In addition, a one-way between-group analysis of variance (ANOVA) was conducted to explore the difference between groups. Participants of this study were divided into three groups in accordance with their nationalities, Taiwanese, Korean, and Japanese. The scores on six factors estimated by dimension reduction of PCA were compared across the three nations. The assumption of homogeneity of variance needs to be tested when comparing three independent groups. Homogeneity of variance is assessed with Levene's test. In order to meet the assumption of homogeneity of variance, the p-value for Levene's test shall above 0.05 . If Levenes Test yielded a p-value above or equal to 0.05 , then the assumption of homogeneity of variance was not violated. The F-statistic was applied, and post-hoc comparisons were made with the Fisher's Least Significant Difference (LSD) test. A p-value of 0.05 was used to indicate significance in the post hoc comparison. If Levene's Test yielded a p-value below 0.05 , it indicated that the assumption of homogeneity of variance had been violated. Then the Brown-Forsythe statistic was used, and the post-hoc analysis was made with the Dunnett's $\mathrm{T} 3$ test.

In order to test the specific difference between group, two sets of comparison were conducted according to the difference of age and marital status. An ANOVA using post hoc analysis was performed for elderly groups ( $\geq 60$ years old) and with young and middle-aged groups ( $<60$ years old) in order to estimate the effect of age. On the other hand, the database was split into group of individuals with partners (married) and group of individuals without partners (single, divorced, and widowed). The comparison with post hoc analysis was conducted to estimate the effect of marital status. We divided the sample by age and marital status to differentiate the effect of the two factors across the three nations. 


\section{RESULTS}

\section{Summary of demographic analysis}

In total, 889 subjects filled in the questionnaires online. Subjects who filled in forms with missing values were excluded from the sample $(n=85)$. The final number of participants included 804 (Taiwanese=291, Korean=293, and Japanese=220). A summary of participant characteristics is listed in Table 1.

\section{Principal component analysis and reliability test}

Regarding the exploratory PCA, the KMO coefficient of sampling adequacy was 0.86 which lies within the acceptable range. Furthermore, the Bartletts' Test of Sphericity reached statistical significance $(\mathrm{p}<0.01)$, supporting the factorability of the correlation matrix. Principal axis factor analysis was carried out with Varimax rotation to determine the factor solutions. As a result of the analysis, the SISQ was divided into the following six factors. Social distance (item 7, 9, 8, 19, 16) indicated the sensitivity of respondents to self-restraint strategies of COVID 19 including avoiding shopping, traveling and dining outside, keeping social distance, avoiding deep contact and so force. Social anxiety of COVID-19 (items 11, 12, 25) represented the degree to which respondents are anxious about their: personal life, the

Table 1. Sociodemographic characteristics of participants $(\mathrm{N}=804)$

\begin{tabular}{lcccr}
\hline & Japan & Taiwan & Korea & Total \\
\hline Effective response & 220 & 291 & 293 & 804 \\
Gender & & & & \\
Male & $115(52.3)$ & $97(33.3)$ & $165(56.3)$ & 377 \\
Female & $104(47.3)$ & $191(65.6)$ & $128(43.7)$ & 423 \\
Others & $1(0.5)$ & $3(1.0)$ & $0(0.00)$ & 4 \\
Age & & & & \\
Less than 20 & $46(20.9)$ & $3(1.0)$ & $1(0.3)$ & 50 \\
20-29 & $75(34.1)$ & $30(10.3)$ & $59(20.2)$ & 164 \\
30-39 & $37(16.8)$ & $44(15.1)$ & $37(12.7)$ & 118 \\
40-49 & $32(14.5)$ & $83(28.5)$ & $69(23.6)$ & 184 \\
50-59 & $16(7.3)$ & $95(32.6)$ & $87(29.8)$ & 198 \\
60-69 & $12(5.5)$ & $33(11.3)$ & $38(13.0)$ & 83 \\
Over 70 & $2(0.9)$ & $3(1.0)$ & $1(0.3)$ & 6 \\
No response & $0(0)$ & $0(0)$ & $1(0.3)$ & 1 \\
Marriage & & & & \\
Single & $140(63.6)$ & $77(26.6)$ & $88(30.1)$ & 305 \\
Married & $67(30.5)$ & $187(64.5)$ & $198(67.8)$ & 452 \\
Divorced & $8(3.6)$ & $17(5.9)$ & $5(1.7)$ & 30 \\
Widow & $4(1.8)$ & $7(2.4)$ & $1(0.3)$ & 12 \\
Single with family & $1(0.5)$ & $2(0.7)$ & $0(0.0)$ & 3 \\
No response & $0(0)$ & $1(0.3)$ & $1(0.3)$ & 2 \\
\hline Datare presented as & & & &
\end{tabular}

Data are presented as $\mathrm{N}(\%)$ economy and political situations. Social desirability (items 22, $24,4)$ indicated the degree to which respondents perceive the reliability of government policies in addressing the pandemic (e.g. mask control, infection control, infection prevention). Social cost (items 10,23,3) indicated the reaction and sensitivity of respondents to the social cost of COVID -19 (investing time and money for daily lives, toilet paper, masks and sanitizers). Social adaptation (items 14, 17, 13, 15) represented the degree to which respondents made efforts to prevent infection (canceling international trip, avoiding people coughing and those who come from pandemic countries). Social information (items $1,20,21)$ represented the degree as to which respondents were willing to collect information about COVID 19. Our results verified these six-factor solutions based on 21 original items, and it explained $52.02 \%$ of the total variance, which is within the acceptable range. The internal consistency coefficients (Cronbach's alpha) of each subscale were within the 0.43 to 0.77 range, and most of them reached the minimal requirement of values at $0.5 .^{23}$ Other information is shown in Table 2.

\section{One-way ANOVA}

The one-way ANOVA indicated that there was a statistically significant difference at the $\mathrm{p}<0.01$ level in the factors of: social distance $(\mathrm{F}[2,801]=22.585, \mathrm{p}<0.01)$, social adaptation $(\mathrm{F}[2$, $801]=13.705, \mathrm{p}<0.01)$, and social information $(\mathrm{F}[2,801]=14.268$, $\mathrm{p}<0.01$ ) for three nationality groups. The other variables (social desirability, social anxiety and social costs) violated the hypothesis of homogeneity of variances, thus we failed to obtain the statistical significance for these variables.

Post-hoc comparisons estimated with the LSD test demonstrated that the mean scores of social distance for all three countries were significantly different; the score for Japanese was the highest $(0.32 \pm 0.98)$, followed by Taiwanese $(0.03 \pm 0.95)$, with the Koreans the lowest $(-0.27 \pm 0.99)$. Regarding social adaptation, the scores of the Taiwanese were significantly lower $(-0.25 \pm$ 1.01) than the scores for the other two countries. The Japanese $(0.12 \pm 0.97)$ and Koreans $(0.15 \pm 0.97)$ did not differ significantly. Finally, scores of social information for Koreans was significantly higher $(0.25 \pm 0.93)$ than that of the other two nations. The Taiwanese $(-0.02 \pm 0.99)$ and Japanese $(-0.01 \pm 1.04)$ had no significant difference in their scores. The remaining data is listed in Table 3.

\section{One-way ANOVA among different age groups ( $\geq 60$ years or $<60$ years)}

The one-way ANOVA for young and middle-aged groups ( $<60$ years old) demonstrated that there was a significant difference in social distance $(\mathrm{F}[2,711]=18.007, \mathrm{p}<0.01)$, social adaptation $(\mathrm{F}[2,711]=13.603, \mathrm{p}<0.01)$, and social information $(\mathrm{F}[2,711]=13.042, \mathrm{p}<0.01)$ for three nationalities. Other three 
Table 2. Principle component analysis for COVID-19 Societal Influences Survey Questionnaire

\begin{tabular}{|c|c|c|c|c|c|}
\hline \multirow[b]{2}{*}{ Components/items } & \multicolumn{3}{|c|}{ Principle component analysis (Varimax Rotation) } & \multirow{2}{*}{$\begin{array}{c}\text { Reliability } \\
\text { Cronbach's alpha }\end{array}$} & \multirow[b]{2}{*}{ Factor loading } \\
\hline & $\begin{array}{c}\text { Sum of squared } \\
\text { loading (Eigenvalue) }\end{array}$ & $\begin{array}{c}\text { Variance } \\
\text { explained (\%) }\end{array}$ & $\begin{array}{c}\text { Cumulative variance } \\
\text { explained (\%) }\end{array}$ & & \\
\hline Social distance & 5.628 & 22.512 & 22.512 & 0.773 & \\
\hline SISQ-7 & & & & & 0.788 \\
\hline SISQ-9 & & & & & 0.733 \\
\hline SISQ-8 & & & & & 0.728 \\
\hline SISQ-19 & & & & & 0.664 \\
\hline SISQ-16 & & & & & 0.538 \\
\hline Social anxiety & 2.164 & 8.654 & 31.166 & 0.652 & \\
\hline SISQ-11 & & & & & 0.756 \\
\hline SISQ-12 & & & & & 0.751 \\
\hline SISQ-25 & & & & & 0.581 \\
\hline Social desirability & 1.624 & 6.496 & 37.662 & 0.449 & \\
\hline SISQ-22 & & & & & 0.807 \\
\hline SISQ-24 & & & & & 0.541 \\
\hline SISQ-4 & & & & & 0.441 \\
\hline Social costs & 1.426 & 5.704 & 43.366 & 0.426 & \\
\hline SISQ-10 & & & & & 0.629 \\
\hline SISQ-23 & & & & & 0.611 \\
\hline SISQ-3 & & & & & 0.611 \\
\hline Social adaptation & 1.130 & 4.522 & 47.888 & 0.585 & \\
\hline SISQ-14 & & & & & -0.617 \\
\hline SISQ-17 & & & & & -0.473 \\
\hline SISQ-13 & & & & & -0.467 \\
\hline SISQ-15 & & & & & -0.458 \\
\hline Social information & 1.033 & 4.133 & 52.021 & 0.639 & \\
\hline SISQ-1 & & & & & -0.779 \\
\hline SISQ-20 & & & & & -0.715 \\
\hline SISQ-21 & & & & & -0.423 \\
\hline
\end{tabular}

Kaiser-Meyer-Olkin (KMO) Measure of Sampling Adequacy: 0.864, Bartlett's Test of Sphericity: $<0.001$. COVID-19, coronavirus disease of 2019; SISQ, Societal Influences Survey Questionnaire

variables did not achieve statistical significance. In addition, the post-hoc comparisons estimated with LSD test demonstrated that the mean scores of social distances for all three countries were significantly different; the score for the Japanese was the highest, followed by Taiwanese, and then the Koreans. For social adaptation, scores of the Taiwanese were significantly lower than the scores for the other two countries. The Japanese and Koreans did not differ significantly from each other. Finally, the score of social information for Koreans was significantly higher than that of the other two nations. Both Taiwanese and Japanese had no significant difference in their scores. The detailed data is listed in Table 4.

For the elderly groups ( $\geq 60$ years), the ANOVA indicated significant differences for the factor social distance $(F[2,86]=$
3.939, $\mathrm{p}=0.023)$, social anxiety $(\mathrm{F}[2,86]=8.999, \mathrm{p}<0.01)$, social desirability $(\mathrm{F}[2,86]=8.920, \mathrm{p}<0.01)$, social costs $(\mathrm{F}[2,86]=$ $17.321, \mathrm{p}<0.01)$, and social information $(\mathrm{F}[2,86]=3.808, \mathrm{p}=$ 0.026 ) for all three nations. After testing with post-hoc comparisons, the mean score of social distance for all three countries indicated that the score for Japanese was significantly higher than for Koreans. Scores for the Taiwanese revealed no significant differences with Japanese or Koreans. Regarding social anxiety, scores of Koreans and Japanese were significantly higher than the scores of the Taiwanese. The Japanese and Koreans did not differ significantly from each other. About social desirability, scores of Taiwanese and Koreans were significantly higher than the scores of Japanese. The Taiwanese and Koreans did not differ significantly from each other. For social costs, 
Table 3. Comparison between three nations using ANOVA with post hoc test for SISQ $(N=804)$

\begin{tabular}{|c|c|c|c|c|c|}
\hline & Mean & Standard deviation & Homogeneity of variances & ANOVA F-value (p-value) & Post hoc (LSD) \\
\hline Social distance & & & $0.893^{\mathrm{a}}$ & $22.585(<0.001)^{*}$ & $\mathrm{Jp}>\mathrm{Tw}>\mathrm{Kr}$ \\
\hline Taiwan & 0.029 & 0.951 & & & \\
\hline Korea & -0.266 & 0.989 & & & \\
\hline Japan & 0.316 & 0.985 & & & \\
\hline Social anxiety & & & $<0.001$ & 61.680 (N.S.) & N.S. \\
\hline Taiwan & -0.485 & 1.057 & & & \\
\hline Korea & 0.264 & 0.803 & & & \\
\hline Japan & 0.290 & 0.916 & & & \\
\hline Social desirability & & & $<0.001$ & 202.128 (N.S.) & N.S. \\
\hline Taiwan & 0.458 & 0.721 & & & \\
\hline Korea & 0.244 & 0.833 & & & \\
\hline Japan & -0.931 & 0.908 & & & \\
\hline Social costs & & & 0.028 & 82.508 (N.S.) & N.S. \\
\hline Taiwan & 0.535 & 0.980 & & & \\
\hline Korea & -0.403 & 0.831 & & & \\
\hline Japan & -0.170 & 0.921 & & & \\
\hline Social adaptation & & & $0.732^{\mathrm{a}}$ & $14.154(<0.001)^{*}$ & $\mathrm{Jp}, \mathrm{Kr}>\mathrm{Tw}$ \\
\hline Taiwan & -0.245 & 1.005 & & & \\
\hline Korea & 0.153 & 0.972 & & & \\
\hline Japan & 0.120 & 0.972 & & & \\
\hline Social information & & & $0.401^{\mathrm{a}}$ & $14.757(<0.001)^{*}$ & $\mathrm{Kr}>\mathrm{Jp}, \mathrm{Tw}$ \\
\hline Taiwan & -0.160 & 0.992 & & & \\
\hline Korea & 0.248 & 0.934 & & & \\
\hline Japan & -0.118 & 1.035 & & & \\
\hline
\end{tabular}

${ }^{a}$ the assumption of Homogeneity of variance (>0.05) for one-way ANOVA was not violated; *significant at the 0.05 level. Jp, Japan; Kr, Korea; Tw, Taiwan; N.S., non-statistical significance; ANOVA, analysis of variance; SISQ, Societal Influences Survey Questionnaire, LSD, Least Significant Difference

scores of the Taiwanese and Japanese were significantly higher than the scores of the Koreans. The Japanese and Taiwanese did not differ significantly from each other. Finally, the scores of social information for Koreans was significantly higher than Japanese. Scores of the Taiwanese revealed no significant difference with Japanese or Korean. The detailed data are listed in Table 5 .

\section{One-way ANOVA among different groups of marital status (with or without partners)}

Among the subjects with partners, the result of ANOVA demonstrated that there was a significant difference in social distance, social anxiety, social desirability, social adaptation, and social information for three nationalities. In the factor of social distance, the post-hoc analysis demonstrated that scores of Japanese were more than Taiwanese, and scores of Taiwanese were more than Koreans. In the factor of social anxiety, the scores of Koreans and Japanese were more than Taiwanese. In the factor of social desirability, the scores of Taiwanese were more than Koreans, and scores of Koreans were more than Japanese. In the factor of social costs, the scores of Taiwanese were more than Japanese, and scores of Japanese were more than Koreans. In the factor of social adaptation, the scores of Koreans were more than Taiwanese and Japanese. In the factor of social information, the scores of Koreans were more than Taiwanese, and scores of Taiwanese were more than Japanese. The detailed data is listed in Table 6.

Similar to subjects with partners, the analysis of comparison revealed that all of the six categories reached statistical significance among those without partners. In the factor of social distance, the post-hoc analysis demonstrated that scores of Japanese were more than Taiwanese and Koreans. In the factor of social anxiety, the scores of Koreans and Japanese were more than Taiwanese. In the factor of social desirability, the scores of Taiwanese and Koreans were more than Japanese. In the factor of social costs, the scores of Taiwanese were more than Jap- 
Table 4. Comparison of SISQ between three nations using ANOVA with post hoc test for subjects under 60 years old $(\mathrm{N}=714)$

\begin{tabular}{|c|c|c|c|c|c|}
\hline & Mean & Standard deviation & Homogeneity of variances & ANOVA F-value (p-value) & Post hoc (LSD) \\
\hline Social distance & & & $0.760^{\mathrm{a}}$ & $18.007(<0.001)^{*}$ & $\mathrm{Jp}>\mathrm{Tw}>\mathrm{Kr}$ \\
\hline Taiwan & 0.043 & 0.941 & & & \\
\hline Korea & -0.236 & 0.987 & & & \\
\hline Japan & 0.311 & 0.997 & & & \\
\hline Social anxiety & & & $<0.001$ & 52.015 (N.S.) & N.S. \\
\hline Taiwan & -0.468 & 1.073 & & & \\
\hline Korea & 0.253 & 0.788 & & & \\
\hline Japan & 0.290 & 0.888 & & & \\
\hline Social desirability & & & 0.001 & 190.049 (N.S.) & N.S. \\
\hline Taiwan & 0.464 & 0.730 & & & \\
\hline Korea & 0.245 & 0.832 & & & \\
\hline Japan & -0.953 & 0.911 & & & \\
\hline Social costs & & & 0.027 & 72.302 (N.S.) & N.S. \\
\hline Taiwan & 0.575 & 0.989 & & & \\
\hline Korea & -0.347 & 0.831 & & & \\
\hline Japan & -0.193 & 0.929 & & & \\
\hline Social adaptation & & & $0.562^{\mathrm{a}}$ & $13.603(<0.001)^{*}$ & $\mathrm{Jp}, \mathrm{Kr}>\mathrm{Tw}$ \\
\hline Taiwan & -0.271 & 0.972 & & & \\
\hline Korea & 0.127 & 1.005 & & & \\
\hline Japan & 0.134 & 0.977 & & & \\
\hline Social information & & & $0.544^{\mathrm{a}}$ & $13.042(<0.001)^{*}$ & $\mathrm{Kr}>\mathrm{Jp}, \mathrm{Tw}$ \\
\hline Taiwan & -0.136 & 0.992 & & & \\
\hline Korea & 0.283 & 0.952 & & & \\
\hline Japan & -0.079 & 1.036 & & & \\
\hline
\end{tabular}

athe assumption of Homogeneity of variance (>0.05) for one-way ANOVA was not violated; *significant at the 0.05 level. Jp, Japan; Kr, Korea; Tw, Taiwan; N.S., non-statistical significance; ANOVA, analysis of variance; LSD, Least Significant Difference

anese and Koreans. In the factor of social adaptation, the scores of Koreans and Japanese were more than Taiwanese. In the factor of social information, the scores of Taiwanese and Japanese were more than Koreans. The detailed data is listed in Table 7.

\section{DISCUSSION}

In the present study, we tested the reliability and validity of the SISQ. It accounted for $52.02 \%$ of the total variance, indicating the six subscales were statistically appropriate. The reliability (Cronbach's alpha) and the construct validity estimated by factor analysis supported the adequacy of the scale's psychometric properties. In accordance with results of ANOVA, the social distance scores for the Japanese were higher than for the Taiwanese, and the Taiwanese scores were higher than Korean scores. The Japanese and Koreans scored significantly higher than Taiwanese for social adaptation. Korean scored considerably higher than Japanese and Taiwanese in scores of social information. The results of from the young and middle-aged groups demonstrated the same difference and was true of the total sample across the three nations. The post-hoc analysis also showed the same order of difference with total participants. However, the results of the elderly group were different from results of the total sample. Furthermore, the results from two comparisons of marital status exhibited similar results except social information. In this factor, Koreans scored higher than other two nations in the comparison of individuals with partners. Whereas, Koreans scored lower than other two nations in the comparison of individuals without partners.

\section{Multi-dimensional assessment of SISQ}

The SISQ used a six-dimensional approach to evaluate the influence of COVID-19 on the public. Assessment of the social distance level is crucial to identify the preparedness for COVID-19. Social distance was suggested by WHO as an effective way to limit the transmission of infectious diseases. ${ }^{24}$ However, the impact of social distance is large. Social distancing and travel restrictions have resulted in a large decrease in 
Table 5. Comparison of SISQ between three nations using ANOVA with post hoc test for subjects equal or above 60 years old ( $N=89)$

\begin{tabular}{|c|c|c|c|c|c|}
\hline & Mean & Standard deviation & Homogeneity of variances & ANOVA F-value (p-value) & Post hoc (LSD) \\
\hline Social distance & & & $0.338^{\mathrm{a}}$ & $3.939(0.023)^{*}$ & $\mathrm{Jp}>\mathrm{Kr}$ \\
\hline Taiwan & -0.079 & 1.023 & & & N.S. Jp=Tw \\
\hline Korea & -0.445 & 1.005 & & & N.S. Kr=Tw \\
\hline Japan & 0.392 & 0.812 & & & \\
\hline Social anxiety & & & $0.435^{\mathrm{a}}$ & $8.999(<0.001)^{*}$ & $\mathrm{Kr}, \mathrm{Jp}>\mathrm{Tw}$ \\
\hline Taiwan & -0.601 & 0.944 & & & \\
\hline Korea & 0.308 & 0.893 & & & \\
\hline Japan & 0.285 & 0.130 & & & \\
\hline Social desirability & & & $0.150^{\mathrm{a}}$ & $8.920(<0.001)^{*}$ & $\mathrm{Tw}, \mathrm{Kr}>\mathrm{Jp}$ \\
\hline Taiwan & 0.412 & 0.658 & & & \\
\hline Korea & 0.246 & 0.857 & & & \\
\hline Japan & -0.605 & 0.816 & & & \\
\hline Social costs & & & $0.840^{\mathrm{a}}$ & $17.321(<0.001)^{*}$ & $\mathrm{Tw}, \mathrm{Jp}>\mathrm{Kr}$ \\
\hline Taiwan & 0.251 & 0.874 & & & \\
\hline Korea & -0.776 & 0.744 & & & \\
\hline Japan & 0.172 & 0.750 & & & \\
\hline Social adaptation & & & 0.016 & 1.717 (N.S.) & N.S. \\
\hline Taiwan & -0.059 & 1.215 & & & \\
\hline Korea & 0.322 & 0.731 & & & \\
\hline Japan & -0.083 & 0.901 & & & \\
\hline Social information & & & $0.399^{\mathrm{a}}$ & $3.808(0.026)^{*}$ & $\mathrm{Kr}>\mathrm{Jp}$ \\
\hline Taiwan & -0.329 & 0.984 & & & N.S. $\mathrm{Tw}=\mathrm{Kr}$ \\
\hline Korea & 0.020 & 0.792 & & & N.S. Tw=Jp \\
\hline Japan & -0.705 & 0.852 & & & \\
\hline
\end{tabular}

${ }^{a}$ the assumption of Homogeneity of variance (>0.05) for one-way ANOVA was not violated; *significant at the 0.05 level. Jp, Japan; Kr, Korea; Tw, Taiwan; N.S., non-statistical significance; ANOVA, analysis of variance; LSD, Least Significant Difference

productivity across all economic sectors, which has had severe ripple effects and placed a heavy burden on society. ${ }^{9}$ In addition, the identification of the social anxiety and the social adaptation provide an indication of mental anguish and changes in behavior. An online survey demonstrated the high prevalence of anxiety symptoms among the people during COVID-19 outbreak in India. ${ }^{25}$ Hence, comprehensive evaluation of these factors could better inform the impact of distress during a pandemic. We also assessed other categories of social influence to extend the applicability of SISQ, including social information, social desirability, and social costs.

\section{Difference of scores for social distance among three nations}

We found that scores of social distances were highest in Japan, indicating they were most diligent in social distancing during the pandemic. Cultural differences may contribute to the divergence of scores. Japanese culture is inherently suited for social distancing, and frequently face mask use prevents viral spread.
Moreover, Japanese customs do not involve handshaking, hugging, or kissing when greeting. ${ }^{26}$ Therefore, it might be relatively tolerable for the Japanese to practice self-restraint during a COVID-19 outbreak. On the other hand, Koreans recruited in the current study scored relatively lower. Few studies have investigated the cultural difference between three nations. However, it might result from governmental policy. Korea had rapidly established a widespread diagnostic capacity, such as drivethrough testing facilities. ${ }^{4}$ Such intensive testing might make Koreans feel safer, thus decreasing the willingness to practice social distance. In Taiwan, there was no massive public testing. Taiwan's government concentrated their efforts at reassuring and educating the public about the policy of infection control, ${ }^{8}$ which was beneficial in creating social distancing.

\section{Difference of scores for social adaptation and social information}

Participants from Taiwan reported significantly lower scores for social adaptation than Korea and Japan. The difference of 
Table 6. Comparison of SISQ between three nations using ANOVA with post hoc test for subjects with partners $(\mathrm{N}=452)$

\begin{tabular}{|c|c|c|c|c|c|}
\hline Item & Mean & Standard deviation & Homogeneity of variances & ANOVA statistic (p-value) & Post hoc analysis \\
\hline Social distance & & & $0.044^{\mathrm{a}}$ & $23.770^{\mathrm{d}}(<0.001)^{*}$ & $\mathrm{Jp}>\mathrm{Tw}>\mathrm{Kr}^{\mathrm{e}}$ \\
\hline Taiwan & 0.149 & 0.850 & & & \\
\hline Korea & -0.282 & 0.998 & & & \\
\hline Japan & 0.454 & 0.717 & & & \\
\hline Social anxiety & & & $<0.001^{\mathrm{a}}$ & $38.653^{\mathrm{d}}(<0.001)^{*}$ & $\mathrm{Kr}, \mathrm{Jp}>\mathrm{Tw}^{e}$ \\
\hline Taiwan & -0.508 & 1.086 & & & N.S. $K r=J p^{e}$ \\
\hline Korea & 0.269 & 0.780 & & & \\
\hline Japan & 0.313 & 0.925 & & & \\
\hline Social desirability & & & $0.016^{\mathrm{a}}$ & $65.225^{\mathrm{d}}(<0.001)^{*}$ & $\mathrm{Tw}>\mathrm{Kr}>\mathrm{Jp}^{\mathrm{e}}$ \\
\hline Taiwan & 0.458 & 0.665 & & & \\
\hline Korea & 0.257 & 0.775 & & & \\
\hline Japan & -0.737 & 0.770 & & & \\
\hline Social costs & & & $0.001^{\mathrm{a}}$ & $85.505^{\mathrm{d}}(<0.001)^{*}$ & $\mathrm{Tw}>\mathrm{Jp}>\mathrm{Kr}^{\mathrm{e}}$ \\
\hline Taiwan & 0.588 & 0.982 & & & \\
\hline Korea & -0.557 & 0.762 & & & \\
\hline Japan & 0.017 & 0.828 & & & \\
\hline Social adaptation & & & $0.609^{\mathrm{b}}$ & $7.411^{\mathrm{c}}(0.001)^{*}$ & $\mathrm{Kr}>\mathrm{Tw}, \mathrm{Jp}^{\mathrm{f}}$ \\
\hline Taiwan & -0.258 & 0.959 & & & N.S. $T w=J p^{f}$ \\
\hline Korea & 0.082 & 0.913 & & & \\
\hline Japan & -0.237 & 0.817 & & & \\
\hline Social information & & & $0.250^{\mathrm{b}}$ & $23.426^{\mathrm{c}}(<0.001)^{*}$ & $\mathrm{Kr}>\mathrm{Tw}>\mathrm{Jp}^{\mathrm{f}}$ \\
\hline Taiwan & -0.282 & 0.899 & & & \\
\hline Korea & 0.171 & 0.874 & & & \\
\hline Japan & -0.571 & 0.750 & & & \\
\hline
\end{tabular}

athe assumption of Homogeneity of variance for one-way ANOVA was violated $(\mathrm{p}<0.05)$; ${ }^{\mathrm{b}}$ the assumption of Homogeneity of variance for one-way ANOVA was not violated ( $\mathrm{p} \geq 0.05$ ); ${ }^{\mathrm{c}} \mathrm{F}$ statistic was used when the assumption of Homogeneity of variance was not violated; ${ }^{\mathrm{d} B r o w n}$ Forsythe statistic was used when the assumption of Homogeneity of variance was violated; ${ }^{\mathrm{P}}$ Post hoc analysis with Dunnett's T3 test; $\mathrm{f}^{\mathrm{P}} \mathrm{\text {osthoc }}$ analysis with Fisher's Least Significant Difference (LSD) test; *statistic significant ( $p<0.05)$; N.S.: non-significant $(\mathrm{p} \geq 0.05)$. ANOVA, analysis of variance

severity for COVID-19 spreading might explain these results. To date, the severity of spreading of COVID-19 in Taiwan is less severe in comparison with the other two nations. ${ }^{27}$ Moreover, government efforts; such as timely border control, application of big data analytics, and experienced teams of officials; made the public less concerned about being infected. ${ }^{8}$ Regarding the result of scores in social information, we found that Koreans were more likely to acquire knowledge of COVID-19 than other two nations. Several factors might explain the higher scores. First, the higher level of concern for infection prompted individuals to search out information about COVID-19. Second, the massive testing for COVID-19 in Korea also encouraged persons to seek updated information, where the massive testing was not performed in Japan and Taiwan. Third, it is possible that cultural difference played a significant role. Previous study indicated that Korean internet users were more active in online communities compared with their Japanese coun- terparts, ${ }^{28}$ and such vitality might give rise to more discussion about hot issues, such as news of COVID-19.

\section{Difference of scores for different groups of age and marital status}

In reference to previous study regarding patients' mortality during COVID-19 pandemic, the threshold of elderly was set at 60 years old..$^{29}$ The distribution of significant difference tested with ANOVA and post-hoc analysis for young and middleaged group were the same as total sample. However, several divergences were found in the results of the elderly group. In short, the difference of social information and social distance were similar to difference of the total sample. It revealed that the scores of social anxieties were lower among Taiwanese than Japanese and Koreans. The lower number of cases of COVID-19 in Taiwan contributed to a lower impact compared with other nations. ${ }^{27}$ The higher scores of social anxieties in Japanese and 
Table 7. Comparison of SISQ between three nations using ANOVA with post hoc test for subjects without partners $(N=350)$

\begin{tabular}{|c|c|c|c|c|c|}
\hline Item & Mean & Standard deviation & Homogeneity of variances & ANOVA statistic (p-value) & Post hoc analysis \\
\hline Social distance & & & $0.649^{\mathrm{a}}$ & $8.259^{\mathrm{b}}(<0.001)^{*}$ & $\mathrm{Jp}>\mathrm{Tw}, \mathrm{Kr}^{\mathrm{c}}$ \\
\hline Taiwan & -0.182 & 1.083 & & & N.S. $\mathrm{Tw}=\mathrm{Kr}^{\mathrm{c}}$ \\
\hline Korea & -0.230 & 0.980 & & & \\
\hline Japan & 0.255 & 1.078 & & & \\
\hline Social anxiety & & & $0.286^{\mathrm{a}}$ & $22.858^{\mathrm{b}}(<0.001)^{*}$ & $\mathrm{Kr}, \mathrm{Jp}>\mathrm{Tw}^{c}$ \\
\hline Taiwan & -0.462 & 0.990 & & & N.S. $K r=J p^{c}$ \\
\hline Korea & 0.252 & 0.857 & & & \\
\hline Japan & 0.279 & 0.914 & & & \\
\hline Social desirability & & & $0.093^{\mathrm{a}}$ & $96.538^{\mathrm{b}}(<0.001)^{*}$ & $\mathrm{Tw}, \mathrm{Kr}>\mathrm{Jp}^{\mathrm{c}}$ \\
\hline Taiwan & 0.455 & 0.818 & & & N.S. $\mathrm{Tw}=\mathrm{Kr}^{\mathrm{c}}$ \\
\hline Korea & 0.209 & 0.946 & & & \\
\hline Japan & -1.017 & 0.952 & & & \\
\hline Social costs & & & $0.611^{\mathrm{a}}$ & $16.512^{\mathrm{b}}(<0.001)^{*}$ & $\mathrm{Tw}>\mathrm{Jp}, \mathrm{Kr}^{\mathrm{c}}$ \\
\hline Taiwan & 0.428 & 0.973 & & & N.S. Jp $=\mathrm{Kr}^{\mathrm{c}}$ \\
\hline Korea & -0.071 & 0.875 & & & \\
\hline Japan & -0.252 & 0.951 & & & \\
\hline Social adaptation & & & $0.782^{\mathrm{a}}$ & $8.836^{\mathrm{b}}(<0.001)^{*}$ & $\mathrm{Kr}, \mathrm{Jp}>\mathrm{Tw}^{\mathrm{c}}$ \\
\hline Taiwan & -0.232 & 1.087 & & & N.S. $K r=J p^{c}$ \\
\hline Korea & 0.294 & 1.080 & & & \\
\hline Japan & 0.277 & 0.995 & & & \\
\hline Social information & & & $0.984^{\mathrm{a}}$ & $3.332^{\mathrm{b}}(0.037)^{*}$ & $\mathrm{Tw}, \mathrm{Jp}>\mathrm{Kr}^{\mathrm{c}}$ \\
\hline Taiwan & 0.066 & 1.113 & & & N.S. $T w=J p^{c}$ \\
\hline Korea & 0.410 & 1.040 & & & \\
\hline Japan & 0.080 & 1.082 & & & \\
\hline
\end{tabular}

${ }^{a}$ the assumption of Homogeneity of variance for one-way ANOVA was not violated ( $\left.\mathrm{p} \geq 0.05\right)$; ${ }^{\mathrm{b}} \mathrm{F}$ statistic was used when the assumption of Homogeneity of variance was not violated; 'Post hoc analysis with Fisher's Least Significant Difference (LSD) test; *statistic significant $(\mathrm{p}<0.05)$; N.S.: non-significant ( $\mathrm{p} \geq 0.05)$. ANOVA, analysis of variance

Koreans resulted from the higher mortality rate for the elderly persons infected with COVID-19. ${ }^{29}$ As a result of social desirability, the elderly subjects in Taiwan and Korea were more confident in their safety than Japanese. As previously mentioned, the rapid reaction to COVID-19 by the authorities in Taiwan ${ }^{8}$ and Korea ${ }^{4}$ made elderly subjects more confident. Finally, the Japanese scored lower on social costs than the Taiwanese or Koreans. Many Japanese routinely wear masks in the winter to avoid transmission of respiratory infections. ${ }^{26}$ Therefore, the preparedness of wearing masks and associated disinfectants among Japanese before COVID-19 pandemic contributed to the relatively lower scores. From the comparison of different marital status, we found the divergence of scores in the factor of social information among Koreans. Married Koreans revealed highest scores than Taiwanese and Japanese, which was comparable to the results from overall samples. However, Koreans without partners were less likely to acquire information about COVID-19 than Taiwanese and Japanese. Although there are no previous evidences addressing this issue, it implicated the predominant effect of marital status in Koreans, and further intervention may be crucial for those without partners to enhance their motivation to acquire information of COVID-19.

\section{Implication of the current study}

Through international cooperation, we have explored the societal influences of COVID-19 across three Northeast Asian countries. The lessons learned from this COVID-19 research can encourage disaster-reduction and support disaster-resilience, thus becoming the cornerstone for recovery interventions in the "post-COVID-19 era." The research results provide a "societal resilience index" model for Taiwan, Korea and Japan during this COVID-19 period and serves as the foundation of disaster-reduction big data science and recovery. Future novel lifestyle activities in epidemic prevention after COVID-19 can be developed between Taiwan, Korea, and Japan, to support health self-management. This research contributes to a knowl- 
edge base that supports the societal resilience of Taiwan, Korea, and Japan in facing future pandemics. The findings also provide a comparative analysis of differences in recovery, thus providing each country a better understanding of their people in epidemic prevention and a means to evaluate recovery and disaster-reduction resilience. As a result, the current study highlights the need for: 1) the development of the community-based intervention to manage the risk of biological disasters, 2) information on eliminating socioeconomic bias, discrimination, stigma and inequalities, and 3) a resilient community empowerment operation model for biological disaster.

French Nobel prize winner in literature Albert ${ }^{30}$ said, "So all a man could win in the conflict between plague and life was knowledge and memories." This interdisciplinary research of the COVID-19 epidemic has increased our knowledge and future infectious disease outbreaks will certainly provide additional knowledge. However, Albert Camus reminds us that such knowledge comes at the cost of many people's demise.

\section{Limitations}

The current study had several limitations that need to be addressed. First, two of the factors had compromising level of reliability. However, the factor loading and overall adequacy of PCA could satisfy the requirement. Second, some missing information in the demographic data limited further analysis. Third, the nature of study based on questionnaires leads to possible recall bias of participants. Fourth, the accuracy of online survey may limit the interpretation of the current results. However, the reliability and validity of the 25 -items SISQ presented in the acceptable range. Finally, the cross-sectional design of the study limited the ability to explore the effects of timeliness.

\section{Conclusion}

With six factors, the SISQ was developed and verified as a reliable tool to comprehensively evaluate multiple domains of social influence. We compared the scores of the six factors across three nations. Differences were found among self-restraint against COVID-19, concern of infection, and awareness of information. In the specific comparison, the elderly subjects demonstrated divergent findings in social anxiety, social desirability, and social costs in comparison with younger group. On the other hand, Koreans without partners were less likely to acquire COVID-19 information, implicating the effect of marital status. The findings of the current study manifested the need for further comparative transnational studies and an opportunity to explore the COVID-19 community-based prevention strategies in reducing and managing the risk of biological disasters. Further studies are warranted to extend the generalizability of the SISQ.

\section{Availability of Data and Material}

The Human Research Ethics Committee of National Cheng Kung University did not approve the authors to make the research data publicly available. Readers and all interested researchers may contact Prof. Satoshi Sugahara (Email: billionaire1210@gmail.com) or Dr. Dian-Jeng Li (E-mail: edcrfvm45@hotmail.com) for details.

\section{Conflicts of Interest}

The authors have no potential conflicts of interest to disclose.

\section{Author Contributions}

Conceptualization: Angela Lo, Vincent Shieh, Satoshi Sugahara, DianJeng Li. Data curation: Bang-Ook Jun, Clay M. Starlin. Formal analysis: Angela Lo, Vincent Shieh, Satoshi Sugahara, Dian-Jeng Li. Investigation: Angela Lo, Bang-Ook Jun. Methodology: Angela Lo, Bang-Ook Jun, Satoshi Sugahara, Dian-Jeng Li. Project administration: Angela Lo, Vincent Shieh. Writing_original draft: Angela Lo. Writing_-review \& editing: Vincent Shieh, Satoshi Sugahara, Dian-Jeng Li.

\section{ORCID iDs}

Angela Lo https://orcid.org/0000-0002-7582-9329

Bang-Ook Jun https://orcid.org/0000-0003-3618-5716

Vincent Shieh https://orcid.org/0000-0002-6247-3597

Clay M. Starlin https://orcid.org/0000-0001-7792-8155

Satoshi Sugahara https://orcid.org/0000-0002-6918-3218

Dian-Jeng Li https://orcid.org/0000-0002-6036-045X

\section{Funding Statement}

None

\section{Acknowledgments}

The authors would like to thank all of the participants from 3 nations. All authors are responsible for the content and writing of the paper.

\section{REFERENCES}

1. Lo HA, Huang JJ, Chen CC, Tsai D, Chou FH, Shieh V. Communitybased epidemic prevention in Taiwan: combating the coronavirus disease-2019 crisis. Disaster Med Public Health Prep 2020;14:e15-e16.

2. Eichenberger R, Hegselmann R, Savage DA, Stadelmann D, Torgler B. Certified coronavirus immunity as a resource and strategy to cope with pandemic costs. Kyklos 2020;73:464-474.

3. Lo A, Huang JJ, Chen CC, Chou FH, Shieh V. From biological safety to social safety: how Taiwan's community centered prevention program controlled the COVID-19 outbreak. J Glob Health 2020;10:020303.

4. Oh J, Lee JK, Schwarz D, Ratcliffe HL, Markuns JF, Hirschhorn LR. National response to COVID-19 in the Republic of Korea and lessons learned for other countries. Health Syst Reform 2020;6:e1753464.

5. Chen H, Shi L, Zhang Y, Wang X, Sun G. A cross-country core strategy comparison in China, Japan, Singapore and South Korea during the early COVID-19 pandemic. Global Health 2021;17:22.

6. Kang J, Jang YY, Kim J, Han SH, Lee KR, Kim M, et al. South Korea’s responses to stop the COVID-19 pandemic. Am J Infect Control 2020; 48:1080-1086.

7. Furuse Y, Ko YK, Saito M, Shobugawa Y, Jindai K, Saito T, et al. Epidemiology of COVID-19 outbreak in Japan, from January-March 2020. Jpn J Infect Dis 2020;73:391-393.

8. Wang CJ, Ng CY, Brook RH. Response to COVID-19 in Taiwan: big data analytics, new technology, and proactive testing. JAMA 2020;323: 1341-1342.

9. Nicola M, Alsafi Z, Sohrabi C, Kerwan A, Al-Jabir A, Iosifidis C, et al. The socio-economic implications of the coronavirus and COVID-19 pandemic: a review. Int J Surg 2020;78:185-193.

10. Talidong KJ, Toquero CM. Philippine teachers' practices to deal with 
anxiety amid COVID-19. J Loss Trauma 2020;25:1-7.

11. WHO. Coronavirus Disease 2019 (COVID-19) Situation Report-57. Geneva: World Health Organization; 2020.

12. Lee SA. Coronavirus anxiety scale: a brief mental health screener for COVID-19 related anxiety. Death Stud 2020;44:393-401.

13. Yang $\mathrm{H}$, Bin $\mathrm{P}, \mathrm{He} \mathrm{AJ}$. Opinions from the epicenter: an online survey of university students in Wuhan amidst the COVID-19 outbreak1. J Chin Govern 2020;5:234-248.

14. Zhang J. People's responses to the COVID-19 pandemic during its early stages and factors: a case study based on a nation-wide survey in Japan. Human Soc Sci Commun 2021;8:37.

15. Dryhurst S, Schneider CR, Kerr J, Freeman ALJ, Recchia G, van der Bles AM, et al. Risk perceptions of COVID-19 around the world. J Risk Res 2020;23:994-1006.

16. WHO. Coronavirus Disease 2019 (COVID-19) Situation Report-51. Geneva: World Health Organization; 2020.

17. Izumi T, Shaw R, Djalante R, Ishiwatari M, Komino T. Disaster risk reduction and innovations. Prog Disaster Sci 2019;2:100033.

18. Li DJ, Kao WT, Shieh V, Chou FH, Lo HA. Development and implementation of Societal Influences Survey Questionnaire (SISQ) for peoples during COVID-19 pandemic: a validity and reliability analysis. Int J Environ Res Public Health 2020;17:6246.

19. Bavel JJV, Baicker K, Boggio PS, Capraro V, Cichocka A, Cikara M, et al. Using social and behavioural science to support COVID-19 pandemic response. Nat Hum Behav 2020;4:460-471.

20. McCoach DB, Gable R, Madura J. Instrument Development in the Affective Domain: School and Corporate Applications (3rd Edition). Hei- delberg: Springer; 2013.

21. Tabachnick BG, Fidell LS. Using Multivariate Statistics. New York, NY: Allyn and Bacon; 2007.

22. Beavers AS, Lounsbury JW, Richards JK, Huck SW, Skolits G, Esquivel SL. Practical considerations for using exploratory factor analysis in educational research. Pract Assess Res Eval 2013;18:1-13.

23. Hinton PR, McMurray I, Brownlow C. SPSS Explained. London: Routledge; 2014.

24. WHO. Coronavirus Disease (COVID-19) Advice for Public. Geneva: World Health Organization; 2020.

25. Roy D, Tripathy S, Kar SK, Sharma N, Verma SK, Kaushal V. Study of knowledge, attitude, anxiety \& perceived mental healthcare need in Indian population during COVID-19 pandemic. Asian J Psychiatr 2020; 51:102083.

26. Iwasaki A, Grubaugh ND. Why does Japan have so few cases of COVID-19? EMBO Mol Med 2020;12:e12481.

27. European Centre for Disease Prevention and Control. COVID-19 Situation Update Worldwide. Solna Municipality: European Centre for Disease Prevention and Control; 2020.

28. Ishii K, Ogasahara M. Links between real and virtual networks: a comparative study of online communities in Japan and Korea. Cyberpsychol Behav 2007;10:252-257.

29. Liu K, Chen Y, Lin R, Han K. Clinical features of COVID-19 in elderly patients: A comparison with young and middle-aged patients. J Infect 2020;80:e14-e18.

30. Albert C. The Plague. London: Hamish Hamilton; 1948. 